\title{
Correction to: A rapid and low-cost protocol for the detection of B.1.1.7 lineage of SARS-CoV-2 by using SYBR Green-based RT-qPCR
}

\author{
Fadi Abdel Sater ${ }^{1} \cdot$ Mahmoud Younes $^{2} \cdot$ Hassan Nassar $^{3} \cdot$ Paul Nguewa $^{4} \cdot$ Kassem Hamze $^{1}$ (D)
}

Published online: 2 January 2022

(c) Springer Nature B.V. 2021

\section{Correction to Molecular Biology Reports (2021) 48:7243-7249 \\ https://doi.org/10.1007/s11033-021-06717-y}

Unfortunately, the first author's name, Prof. Fadi Abdel sater, was misspelt in the original version of this article. During the production process, the letter "l" was added after the author's name. The author name is corrected with this correction.
The original article has been corrected.

Publisher's Note Springer Nature remains neutral with regard to jurisdictional claims in published maps and institutional affiliations.
The original article can be found online at https://doi.org/10.1007/ s11033-021-06717-y.

Paul Nguewa

panguewa@unav.es

$\triangle$ Kassem Hamze

kassem.hamze@ul.edu.lb

1 Laboratory of Molecular Biology and Cancer Immunology (Covid 19 Unit), Faculty of Science I, Lebanese University, Hadath, Beirut 1003, Lebanon

2 Research Department, Beirut Cardiac Institute, Old Airport Road, Beirut, Lebanon

3 Bahman Hospital, Beirut, Lebanon

4 Department of Microbiology and Parasitology, ISTUN Instituto de Salud Tropical, IdiSNA (Navarra Institute for Health Research), University of Navarra, c/ Irunlarrea 1, 31008 Pamplona, Navarra, Spain 